\title{
AC 2012-3015: ROBOTIC FOOTBALL: AN INTER-UNIVERSITY DESIGN COMPETITION EXPERIMENT
}

\section{Dr. John-David S. Yoder, Ohio Northern University}

John-David Yoder received all of his degrees (B.S., M.S., and Ph.D.) in mechanical engineering from the University of Notre Dame. He is professor and Chair of the Mechanical Engineering Department at Ohio Northern University, Ada, Ohio. He has previously served as Proposal Engineer and Proposal Engineering Supervisor at Grob System, Inc., and Software Engineer at Shaum Manufacturing, Inc. He has held a number of leadership and advisory positions in various entrepreneurial ventures. He is currently a KEEN (Kern Entrepreneurial Education Network) Fellow, and has served as a Faculty Fellow at the Jet Propulsion Laboratory, Pasadena, Calif., and an Invited Professor at INRIA Rhone-Alpes, Monbonnot, France. Research interests include computer vision, mobile robotics, intelligent vehicles, entrepreneurship, and education.

Dr. James P. Schmiedeler, University of Notre Dame

Dr. Michael Milo Stanisic, University of Notre Dame 


\section{Robotic Football: An Inter-university Design Competition Experiment}

\section{Introduction}

Robotics competitions have grown significantly over the past decade. The FIRST competition has inspired many K-12 students [1], robotic soccer competitions have spanned the globe [2], and various professional organizations, including ASME [3] and IEEE [4], have included robotic competitions in their student design competitions.

However, none of these competitions seem to have similarities to many other long-term, successful intracollegiate engineering competitions (such as SAE Baja or Heavy Lift). These competitions inspire students, but also allow teams to improve their designs and technology over the years, rules that change slowly, and clear rules on what can and cannot be "reused" from prior competitions. The result of this is that over the years, a winning Baja car from years ago would struggle to compete in today's competition - teams have gotten much better.

At the University of Notre Dame, a robotic football competition was initiated in the spring of 2008 as the main design project for the capstone course for all senior mechanical engineering students. An advantage of a robotic football game is that the robustness of the students designs and manufacturing skills are tested in a way that they are not in FIRST or related competitions the designs must consider being able to withstand significant impacts. Furthermore, it takes advantage of the high (and growing) popularity of American football on college campuses.

After repeating the competition in 2009 , the coordinating faculty desired to reach out and include another university in the next competition. To do this, it was decided to invite a team of students from Ohio Northern University to design three of the robots for the team. The purpose of this paper is threefold: to describe that process and the progression to a true inter-university competition; to allow other universities can use this paper as a reference when considering design competitions on their campus; and to publicize this event in the hope ofgrowing the number of school involved in this competition. As such, the rules are included in their entirety can be found at ame.nd.edu/robotfootball.

\section{Beginnings of the competition}

In 2007, three alumni of the College of Engineering at the University of Notre Dame approached the Aerospace and Mechanical Engineering Department with the idea of sponsoring a robot football competition. Their vision was to challenge mechanical engineering undergraduates to design robots with some human-like capabilities and to capitalize on the widespread interest in collegiate football in the United States to draw broader attention to the accomplishments of engineering students in general. As a pilot program to investigate the feasibility of developing such a competition within the time and budget constraints of a one-semester senior capstone 
design course, two groups of 5 students each built two prototype robot football players during the spring 2008 semester. Both were remote controlled wheeled robots roughly the size of a computer printer and weighed about 40 pounds each. The "quarterback" robot was essentially a mobile air cannon that "threw" souvenir-sized footballs, and the second robot was essentially a moving catapult.

With the feasibility of students building functioning robots in about 12 weeks demonstrated, the program expanded to a full competition in the spring of 2009. Rules for an eight-on-eight game of modified American football were developed by Michael Stanisic as the instructor of the senior capstone course and the three sponsoring alumni. The rules were designed to retain as many of the features of a traditional football game as possible and to encourage reasonable anthropomorphism in the robots. For example, possession of a loose ball required only physical contact with any part of a robot, but if the robot could pick it up and retain it, it was legal to further advance the ball. Also, dimensions on extendable arms on the robots were limited to approximate dimensions of human arms. Students were divided into two teams of about 35 and given a budget to build 11 robots each. The game was held on the Saturday morning immediately before the spring practice game of the Notre Dame football team, which is known as the Blue/Gold Game. About two hundred fans consisting of other undergraduates, local parents and younger children, and alumni on campus for the Blue/Gold game attended. For this first game, students were allowed to hand place robots in position on the field for each play, but all robots were remote controlled by students on the sidelines. The game was dominated entirely by running, with only one failed pass even attempted. By the end of the second half, the students had gained enough proficiency in controlling the robots that scoring occurred on nearly every possession, with the Gold team winning as the Blue "running back" fumbled the ball on the last play of the game just before entering the endzone for what would have been the go-ahead touchdown.

A number of changes were implemented the following year based on lessons learned from the first game. Improved control of the robots was emphasized by precluding any human from touching a robot on the field other than to remove it due to "injury." To encourage the development of passing capabilities, scoring procedures were modified such that completing a pass by simply hitting a receiver with a thrown ball earned a team more points than scoring a running touchdown. Kicking was also introduced into the game by requiring the construction of a single player that would perform kick-offs, punts, and extra point attempts in the same manner. Students were assigned both to a team (Blue or Gold) and to a functional specialty (actuation, chassis, control, drive train, or mechanisms), but individual teams determined what types and numbers of robot players to build within their given budget. Ten days prior to the game, an NFLstyle "combine" was held in which the students demonstrated the ability of their robots to perform standard tests such as a sprint, precision positioning, center-to-quarterback handoff, and passing accuracy. Students were graded primarily on robot performance at this combine. One distinct advantage of holding the combine was that it forced students to complete construction of 
their robots well in advance of the game, which allowed more time to practice operating them and to correct major flaws prior to the competition itself. The game was moved to the Friday night prior to the Blue/Gold game to attract a larger crowd immediately after the on-campus pep rally. Social media advertising of the game was also introduced via Facebook and Twitter. The Notre Dame head football coach Brian Kelly supported the effort by attending the combine and tweeting to encourage fans to attend the game. As a result of these efforts, the crowd grew to about 600 people for the second game. Despite the rules emphasizing passing, only a few completions were achieved during the game, and the Gold team won again with a superior running attack. The differential drive approach to the drive train on the Gold team proved to yield more maneuverable robots than the rack-and-pinion approach of the Blue team.

\section{Overview of the competition}

For the competition described here, the rules for the 2010-11 academic year will be described. Minor changes have been made for 2011-12 as described below. While the full rules are available online, a brief overview will be provided here.

The robots do not function autonomously - they are remote-controlled by students. The robots are designed as players of 5 different positions: Quarterback, Running Back, Receiver, Kicker, and Lineman. While the kicker is allowed to carry a potential energy source of any kind, all of the other robots are to be battery-powered. Constraints are placed on the overall weight and size of each robot. An accelerometer-based "tackle sensor" must be part of each robot, allowing the robot to be tackled, or temporarily disabled, when it is hit by another robot. This is the central difference between blocking and tackling - a block can be effective without triggering this tackle sensor, while to tackle another robot requires a real "hit" to trigger the sensor. During the game, the rules of football are basically followed, with the exception of scoring changes enacted to encourage passing.

The major challenges involved in design for this project are roughly as follows:

a) Robustness - it is one thing to design a remote-controlled robot, but to make it robust enough to withstand multiple impacts and still function is a considerably more difficult task.

b) Weight vs. Power - students must balance the desire for more powerful batteries and motors with the weight restriction.

c) Teamwork - students must work together in designing the robots, as the rules for interface between robots are intentionally vague.

d) Ball transfer - the ball must be "snapped" to the quarterback. It can be dropped, handed, etc., but the ball must be transferred between the two machines.

e) Handling - being able to easily control the robots is a must. 
f) Passing - the biggest challenge has been to successfully complete passes.

g) Budget - teams are limited in the amount they can spend to build each robot.

\section{Bringing in another university}

During the 2009-10 school year, faculty at Notre Dame began the process of expanding the competition. The goal was to broaden the competition to impact more students and improve the technology.

In the mechanical engineering departments, there are strong connections between Notre Dame (ND) and Ohio Northern University (ONU). Two faculty in the mechanical engineering department at ONU completed their graduate work at ND, in addition to the Dean. ONU and ND faculty have collaborated on proposals and education-related grant efforts. A faculty member from ND serves on the mechanical engineering program working group at ONU. Based on this relationship, it was felt that ONU would be a good first partner for this competition.

It was not felt that ONU would be able to field a complete team of competitors within its senior design sequence. Unlike ND, students at ONU work on a variety of different projects for their capstone project, so not enough students would be available to construct a complete team. Therefore ONU was asked to create three different players for the competition for one of the teams. Timing challenges also existed, as ONU students have a year-long capstone effort with projects selected in their junior year, while ND students have capstone in the spring semester only. Students were given old robots to use, but only as a source for parts/subassemblies. Using old robots (especially motors, gears, controllers, tackle sensors, and control boards) helps limit costs. If a university were to start a team of robots, the likely cost would be over $\$ 1000$ per machine, but less than $\$ 2000$, depending on design decisions made by the students. Outside funding from grants and interested alumni have been used to offset these costs.

The format of the competition was changed to accommodate this arrangement, putting the robots into a "combine" and then a draft to select teams rather than assigning teams from the beginning. Scheduling was a challenge, since the small private university operates on the quarter system and has a year-long capstone project, while the large private university has a one-semester course. Furthermore, rules were changed "on-the-fly" to try to accommodate the cross-university project. 
The competition took place in the spring of 2011 with mixed results. One team was "mixed" between two universities, and that team lost the competition. There were a variety of reasons for this, only some of which were related to the team being made up of students from both schools. Students were surveyed on their learning experience on both teams, and the results of that survey will be presented later in the paper. Video of the competition can be seen at [5].

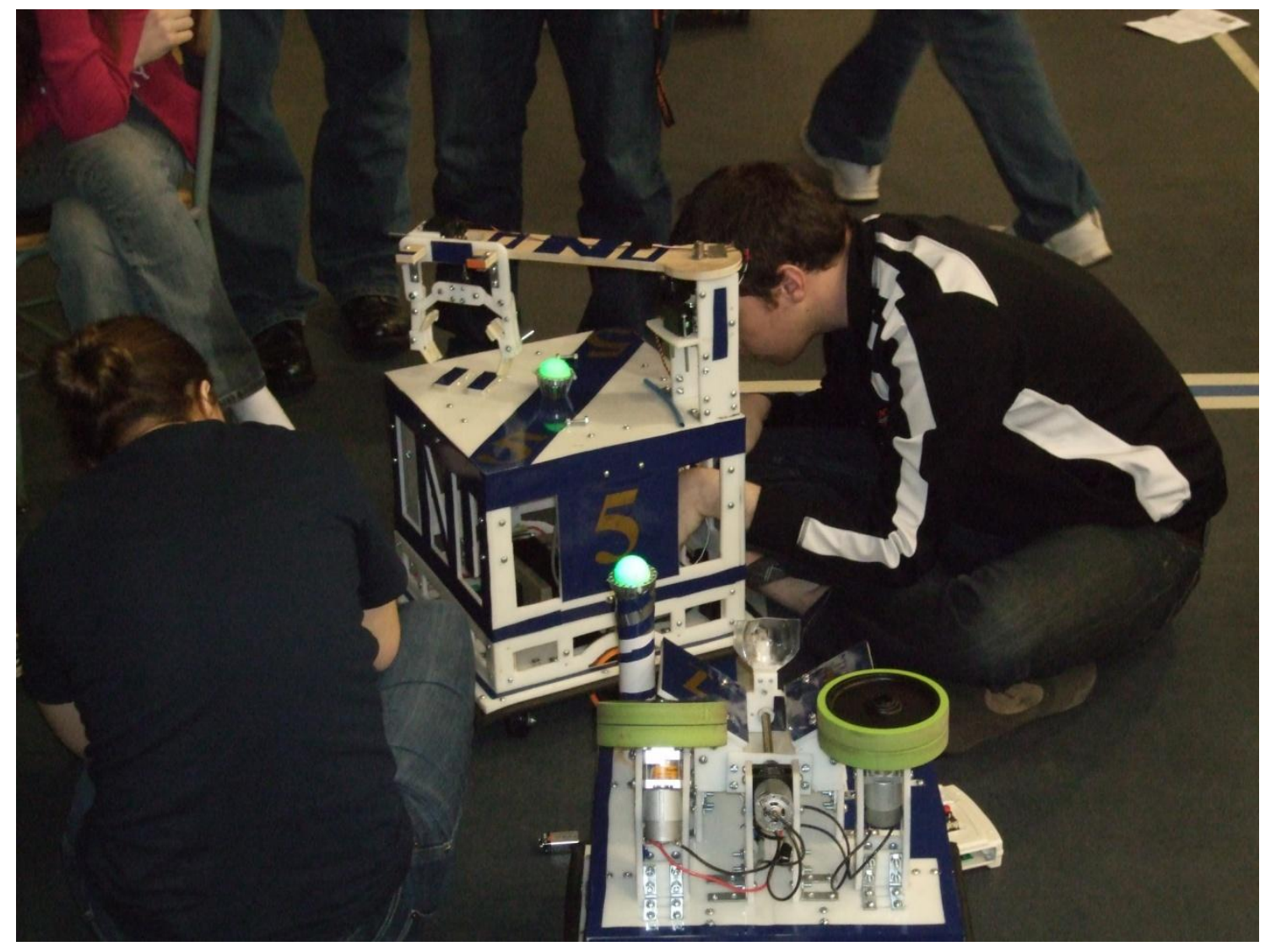

Figure 1: Students work on a robot on game day 


\section{Lessons learned}

While the faculty and students have improved the competition over the first three years, the basic design challenges remain the same. As with many competitions, part of what separated the best robots from weaker ones was practice - teams that just completed their robots in time for the competition were not very skilled at controlling them accurately. Also as with many competitions, robustness is important and teams had to deal with repairs during the event (see figure 1). In the first competitions, students had communication issues with the robots - each robot must be programmed with a unique channel number. This was not debugged in advance, since the first time all the robots were in the room together was on competition day. This problem has been resolved by assigning channel numbers ahead of time.

Ball transfer and passing remain the two biggest challenges. In the 2011 competition, the losing team had several turnovers caused by "muffed" snaps and also by difficulty in fielding kickoffs. The "snap" was something added to the rules for this competition - and while all the teams could accomplish this in practice, it proved very difficult to execute snaps in the game because of inaccuracy in lining up robots (the relationship between the center and the quarterback had to be very accurate for the center to work). This is a challenge since students have to line up their robots before each snap using only their controller - just as real football players much sometimes rush back to the line of scrimmage for the next play. It will be interesting to see whether or not students are able to correct this problem in the 2012 competition by designing a "snap" that is more tolerant of poor alignment.

Significant work was accomplished by the students in the spring of 2011 in order to improve the odds of completing a pass (completing a pass requires only that the receiver be hit by the ball). A video of the results in practice can be seen here [6]. However, despite successfully showing the technical ability to have the quarterback "detect" a receiver based on an infrared beacon, very few passes were actually completed in the game. The pace of the game and the pass rush was much too fast for this ability to really work well.

A survey that was used regarding the competition is included as Appendix A. A few points from the results of the survey are included here. The survey was administered late in the school year, which resulted in a lower-than-desired response rate of $42 \%$ (27/64). Twenty-five of the twentyseven respondents $(93 \%)$ agreed or strongly agreed that they enjoyed working on the project. Twenty-four agreed or strongly agreed (89\%) that they learned a lot on the project.

Twenty-six of the respondents (96\%) cited manufacturability as an applicable constraint. Twenty-four (89\%) cited the competition rules and twenty-three (85\%) felt an economic constraint was part of the project. After those three, the top constraints listed were health and safety (10 students, 37\%) and social constraints (7 students, 26\%). This indicates that in terms of the ABET list of constraints applicable to a culminating experience, manufacturability and economic constraints were the only ones that most students felt applied. 
When students were asked what was most important to the competition, 11 selected practice, 7 selected design, 7 selected durability, and 1 selected teamwork. $100 \%$ of the ONU respondents selected practice as the most important aspect, perhaps because they felt the inability for them to practice as a team hurt them in the competition. As a design project in the curriculum, the limited emphasis (as measured by the survey) on design and teamwork is a major concern.

Student responses on the survey's open-ended question ("Please describe the hardest decision you had to make for your project, and how you made that decision") indicated that decisions were based largely either on group voting, or on past choices. Choices typically involved cost, manufacturability, and giving up features.

From an educational perspective, the initial main objectives included following the design process, building machines "from scratch" to meet a specification, and, very importantly, having to build an electromechanical system that works, and that can withstand use in a "harsh environment". Students must build the mechanics, but also do the wiring, interfacing, and update software to work on their machine. However, as students can increasingly rely on the work previous teams, the design element of the competition has decreased - note that the students do not cite making decisions primarily on a technical basis. Furthermore, the ABETlisted constraints for design were not selected by most of the students on the survey (though 10 students selected Health and Safety as one of the three most important aspects, 6 selected Social constraints, and 3 selected ethical constraints). A series of changes are underway (see below) in order to increase the design emphasis.

All but one of the blue team respondents (93\%) either agreed or strongly agreed that being on a team made up of players from both teams hurt them in the competition. The same percentage $(93 \%)$ disagreed or strongly disagreed that being on a split team had hurt their educational experience.

\section{Conclusions and future work:}

The competition clearly generates a lot of excitement on the campus. Over 700 people were in the audience as the 2010-11event (see Figure 2). This is a very large turnout compared to many other competitions. It is felt that holding the event on campus and pairing it with the spring football game contributes to this - but the audience is also made up of $\mathrm{K}-12$ students. The university students are asked to talk with the K-12 students after the competitions and let them control the robots in an effort to do some outreach. It is hoped that this outreach can be extended - it is expected that one team in 2011-12 will include a few high school students. 


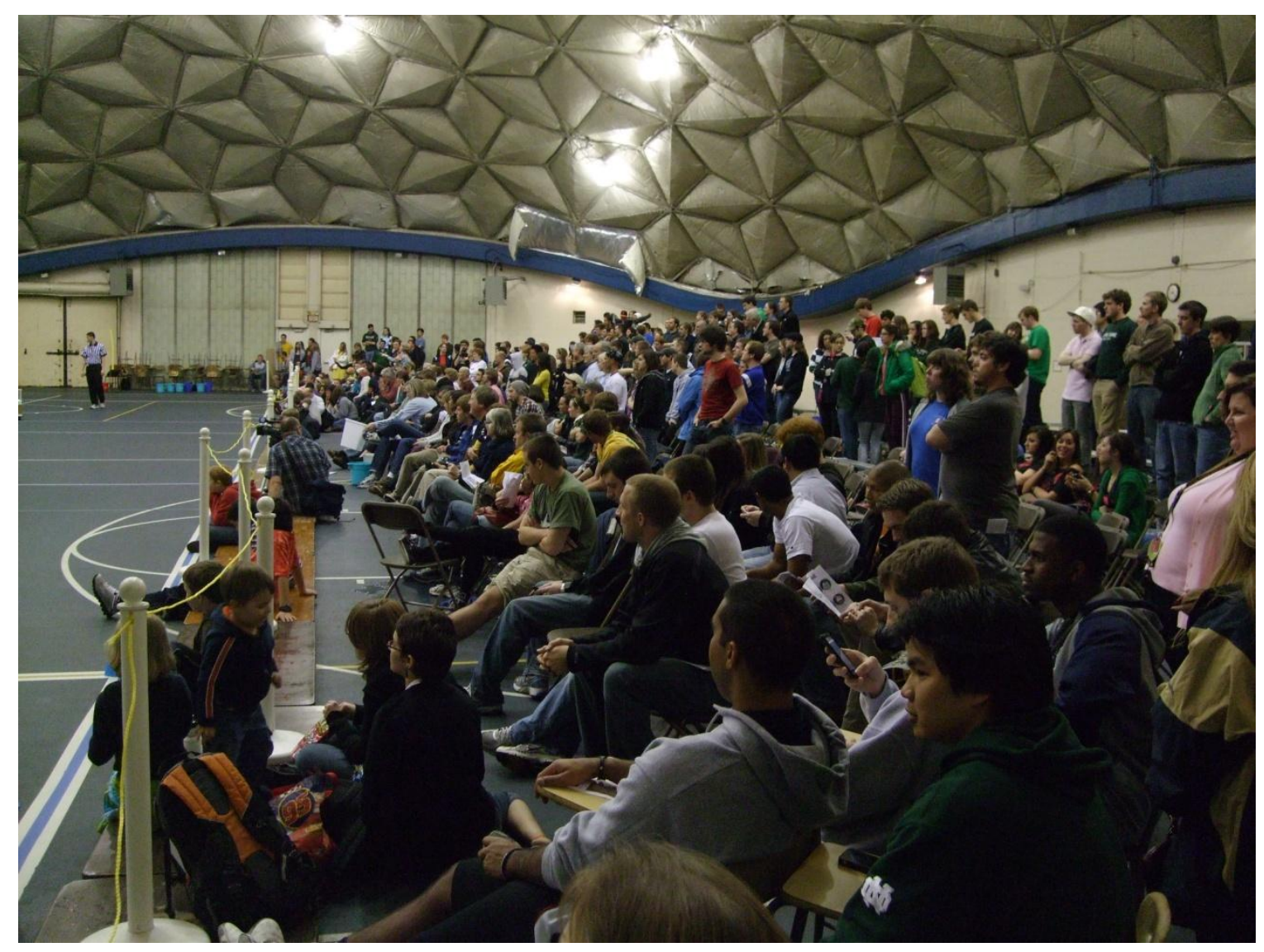

Figure 2: Part of the audience for the competition

One major concern has been the over-reliance on previous designs. There were some significant advances in 2010-11. In particular, the improved ability to find receivers was a good technical addition, and the kickers both performed very well despite using different technologies.

However, many of the other design decisions (for example, what battery or motor to use) were made simply by duplicating what the previous class had done. Because of this concern, major changes are underway.

The two universities are moving forward with a competition this year in which each school will field a full team. While that is just starting at this point, results can be presented at the conference. Both teams include a minimal number of students (roughly one per robot instead of a team for each robot). It is hoped that long-term, this competition will continue as a student activity, rather than as part of the senior design sequence.

The originators of this event would like it to continue long-term as an intercollegiate event. As such, this paper has attempted to describe the event, and the evolution from a single course at one university to two universities. The rules of the competition have been made available. The authors would be very pleased to work with any faculty who have an interest in having students at their school be part of this competition, as this paper alone likely is not enough information to start a competition on additional campuses. 


\section{References}

[1] "Welcome to the FIRST Robotics Competition" Online: http://www.usfirst.org/roboticsprograms/frc, accessed 1/2/12.

[2] "Robocup Soccer" Online: http://www.robocup.org/robocup-soccer/, accessed 1/2/12.

[3] "Scenes from previous design competitions", Online:

http://origin.eastbaymedia.com/ asme/asx/studentdesign/promo.asx, accessed 1/2/12.

[4] Ackerman, A. "Meet the New World's Fastest Micromouse Robot," IEEE Spectrum, November 21, 2011.

[5] "Robotic Football: Notre Dame Initiates Intercollegiate Competition" Online: http://www.youtube.com/watch?v=riCLMHQnWVc, accessed 1/11/12.

[6] "Notre Dame Robot Football 2011 Blue Team Passing", Online: http://www.youtube.com/watch?v=adfqoBybthI, accessed 1/3/12. 


\section{APPENDIX A: SURVEY}

1. I enjoyed working on this project.

$\begin{array}{llll}\text { Strongly Agree } & \text { Agree } & \text { Unsure } & \text { Disagree }\end{array}$

2. I learned a lot working on this project.

$\begin{array}{llll}\text { Strongly Agree } & \text { Agree } & \text { Unsure } & \text { Disagree }\end{array}$

3. Which of these constraints do you think were part of your project? Circle all that you think applied.

Competition Rules Economic Environmental

Political Ethical Health and Safety

Sustainability Social $\quad$ Manufacturability

4. Which of the following were most important at the competition? Circle only 1 :

Design

Practice

Durability

Teamwork

Programming

5. Please describe the hardest decision you had to make for your project, and how you made that decision.

BLUE TEAM ONLY

6. Working on a team at two schools hurt our team at the competition:

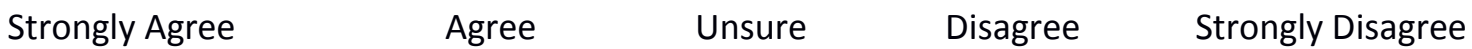

7. Working on a team at two schools hurt our education experience:

Strongly Agree

Agree

Unsure

Disagree

Strongly Disagree

N

G 